\title{
The light express roadshow: a case study in a successful secondary school's photonics outreach activity
}

Pearl John, Keith Wilcox, Sunil Patel

Pearl John, Keith Wilcox, Sunil Patel, "The light express roadshow: a case study in a successful secondary school's photonics outreach activity," Proc. SPIE 9664, Ninth International Topical Meeting on Education and Training in Optics and Photonics, 96641R (24 October 2005); doi: 10.1117/12.2207708

SPIE Event: Ninth International Topical Meeting on Education and Training in Optics and Photonics, 2005, Marseille, France 


\title{
Ref ETOP048
}

\section{The Light Express Roadshow: a Case Study in a Successful Secondary School's Photonics Outreach Activity}

\author{
Pearl John, Keith Wilcox and Sunil Patel
}

\begin{abstract}
The schools outreach programme of the School of Physics and Astronomy at the University of Southampton has reached over six thousand school children during the last five years. The outreach programme centres on a traveling 'Light Express Roadshow'; a laser light show and photonics lecture provided free to schools throughout the South East of England. This paper explores the technical, educational and funding issues associated with providing a successful outreach activity to inspire and encourage a new generation of physicists.
\end{abstract}

\section{Summary}

The United Kingdom has suffered from a sharp decline in the number of students choosing to study physics at University. This decline has been described as potentially disastrous for the country as it will affect the UK's long-term ability to be among the world leaders in applied technology. The School of Physics and Astronomy at the University of Southampton (one of the top three physics departments in the United Kingdom) is trying to reverse the trend and increase student numbers by using a traveling laser light show and spectacular photonics lecture to encourage more students to study physics. This paper explores the benefits and challenges associated with using a traveling, professional laser light show to promote the study of physics to secondary school pupils in their schools.

The Light Express Roadshow was set up in the year 2000 with the intention of raising awareness of the emerging photonics industry. The University of Southampton conducts a huge amount of leading-edge research photonics and has established several high-profile spin-out companies. Southampton research into optical fibres from the mid-1960s onwards has been key to the emergence of modern communications technology, and the University's Optoelectronics Research Centre (ORC) is still a world-leader in this field. The Light Express Roadshow aims to explain how photonics is used in telecommunications, providing the underlying technology of the internet, and the lecture is based on the National Curriculum for Physics at GSCE and ' $A$ ' levels.

Over sixty Light Express presentations have been given over the last five years. These presentations have included schools visits, Light Express days at the University, a trip to the prestigious Albert Hall in London for the British Association Science Day in 2001, a performance in a church and laser light show against the medieval monument in Southampton's city centre. Approximately six thousand members of the public, teachers and school children have seen the Light Express Roadshow perform.

The Light Express Roadshow relies on a one watt mixed argon/krypton ion gas laser, an eight channel polychromatic acousto-optic modulator, Cambridge $6800 \mathrm{HP}$ scanners and Pangolin laser lightshow software. Overhead beam shows are used - similar to those used in nightclubs to catch the secondary students' attention, and a popular soundtrack is played along with the laser show. During the photonics lecture the optics in the light show are set using adjustable 
mirrors for several different demonstrations; such as a Michelson interferometer, Tyndall's (or Colladon's) experiment, Young's slits experiment and fluorescence. The Light Express Roadshow's experiments are designed to illustrate the main differences between lasers and other light sources, showing directionality, spectral purity and coherence. The uses of lasers and fibre optics in the telecommunications industry are demonstrated, showing total internal reflection of a laser beam inside a water tank and inside a strea $\mathrm{m}$ of water. Finally, the laser beam is launched into an optical fibre that has been hung up around the school hall - causing the whole fibre to glow.

Safety is a major concern during the show and approximately three hours are spent setting up the equipment in school halls to ensure that the audience is safe and that legal safety requirements are adhered to. A thorough risk assessment is provided for each show. Postgraduate helpers and participating academic staff members have all been laser safety trained in the School of Physics and Astronomy's laser safety programme and receive eye testing.

There are numerous benefits for the schools who request a performance from the Light Express Roadshow. The Roadshow is designed to cover National Curriculum physics topics such as; characteristics of waves, the electromagnetic spectrum and telecommunications technology, using equipment that the school teacher will not otherwise have access to. The Light Express Roadshow also introduces teachers and students to 'cutting edge' research topics and researchers in physics and photonics, providing them with a valuable resource. The Light Express Roadshow currently has a long waiting list of schools wanting visits. Over 100 schools have contacted the University of Southampton requesting visits by the Roadshow and every school visited has requested a return visit.

The Light Express Roadshow aims to challenge and address a number of stereotypes about physics and physicists, which may be partly responsible for the low numbers of students considering physics as a subject for study or career path to follow. For example, women are under-represented in the sciences. The Light Express Roadshow involves female physics students to undermine the stereotype that only men study physics. Female researchers are particularly encouraged to take part in helping on the Light Express Roadshow to act as role models for the younger students.

There is also a general view amongst the public that physicists are middle-aged and lack social skills. It is hoped that by using popular music in the Light Express Roadshow and involving post graduate students that the school pupils will see that research scientists can be young and dynamic. There is also a lack of understanding about career opportunities open to physics graduates. The Light Express Roadshow lecture attempts to raise public awareness of the wide range of careers available to physics graduates. The Roadshow also emphasizes familiar technology that relies on physics research, such as mobile phones, cable TV, CD and DVD players. The Light Express Roadshow lecture explains the technology behind the internet.

The Light Express Roadshow was originally funded by the South East England Opto-electronics Skills Delivery Plan (SEOS) Project grant to raise awareness of the Photonics industry. (The Roadshow has also received support from the ORC, the Institute of Physics and the Particle Physics and Astronomy Research Council). Once the SEOS project and grant had ended, the University of Southampton awarded its School of Physics and Astronomy an 'Action on Access' 
grant to reach out to inner city middle school pupils from disadvantaged backgrounds. The objective for the year-long project - to give 20 performances in local schools - was met and the Roadshow was deemed a great success. To further build on that success, the School of Physics and Astronomy chose to fund the Roadshow for marketing and recruitment purposes.

The Light Express Roadshow is beneficial to the University of Southampton's School of Physics staff and students in many different ways. The Roadshow raises the profile of the School of Physics and Astronomy at local, regional, national and international levels. There is however, a difficulty in evaluating the success of the project now that it has been considered a marketing and recruitment tool. There is currently very little quantitative data available to suggest that the Light Express Roadshow can specifically raise the number of students who choose to study physics at the University of Southampton in particular. The students targeted by the Light Express Roadshow have been aged 15-16 years, so it will take at least three to four years to assess the impact of the project. Although the Light Express Roadshow is a unique outreach activity valued by secondary schools, it is more difficult to evaluate its success under these new funding conditions. 